\title{
Ambition meets reality: lessons from the taro boom in Nicaragua
}

\author{
Jason Donovan \\ International Centre for Research in AgroForestry, Lima, Peru \\ Nigel Poole \\ SOAS, London, UK \\ Keith Poe \\ Consultant, Managua, Nicaragua, and \\ Ingrid Herrera-Arauz \\ Consultant, Matagalpa, Nicaragua
}

Received 17 February 2017

Revised 18 August 2017

3 November 2017

Accepted 18 November 2017

\begin{abstract}
Purpose - Between 2006 and 2011, Nicaragua shipped an average of US\$9.4 million per year of smallholder-produced fresh taro (Colocasia esculenta) to the USA; however, by 2016, the US market for Nicaraguan taro had effectively collapsed. The purpose of this paper is to analyze the short-lived taro boom from the perspective of complex adaptive systems, showing how shocks, interactions between value chain actors, and lack of adaptive capacity among chain actors together contributed to the collapse of the chain. Design/methodology/approach - Primary data were collected from businesses and smallholders in 2010 and 2016 to understand the actors involved, their business relations, and the benefits and setbacks they experienced along the way.

Findings - The results show the capacity of better-off smallholders to engage in a demanding market, but also the struggles faced by more vulnerable smallholders to build new production systems and respond to internal and external shocks. Local businesses were generally unprepared for the uncertainties inherent in fresh horticultural trade or for engagement with distant buyers.

Research limitations/implications - Existing guides and tools for designing value chain interventions will benefit from greater attention to the circumstances of local actors and the challenges of building productive inter-business relations under higher levels of risk and uncertainty.

Originality/value - This case serves as a wake-up call for practitioners, donors, researchers, and the private sector on how to identify market opportunities and the design of more robust strategies to respond to them.

Keywords Markets, Complex adaptive systems, Value chains, Cooperatives, Horticulture,

Development programming, Rural livelihoods

Paper type Research paper

\section{Introduction}

Since the late 1990s, governments and development agencies have enthusiastically embraced market-based approaches, including value chain development (VCD), to reduce rural poverty, generate employment, and create sustainable enterprises (SNV (Netherlands Development Organization), 2005; Department for International Development, 2008; USAID, 2008; Coles and Mitchell, 2011). The approach challenges governments and civil society to look beyond individual actors, such as smallholders or cooperatives, when considering how to achieve development goals. This implies deeper collaboration with downstream buyers and processors, as well as attention to the business environment in which market actors operate. It is argued that by focusing on the value chain and the links between the actors spread along it,

(C) Jason Donovan, Nigel Poole, Keith Poe and Ingrid Herrera-Arauz. Published by Emerald Publishing Limited. This article is published under the Creative Commons Attribution (CC BY 4.0) licence. Anyone may reproduce, distribute, translate and create derivative works of this article (for both commercial and non-commercial purposes), subject to full attribution to the original publication and authors. The full terms of this licence may be seen at http://creativecommons.org/licences/by/4.0/legalcode
\end{abstract}

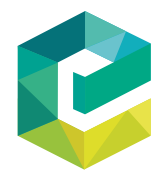

Journal of Agribusiness in Developing and Emerging Economies Vol. 8 No. 1,2018 pp. $77-98$ Emerald Publishing Limited 2044-0839 DOI 10.1108/JADEE-02-2017-0023 
JADEE 8,1

development interventions can better identify common problems and solutions that generate multiple win outcomes. Improved chain relations and overall chain performance are expected to yield tangible benefits in terms of economic performance and, in some cases, poverty reduction. Important factors that have spurred interest in VCD include growing urban demand for addedvalue foodstuffs in developing countries, more stringent quality and food safety standards by governments and private firms, the growth of niche markets (e.g. organic and fair trade), and uncertainties in the production of agricultural raw materials. The potential to include mediumand large-scale businesses as active partners in VCD offers development agencies opportunities for achieving outcomes at a greater scale, with potentially increased impact and sustainability.

For many governments and development organizations, VCD in fresh horticultural products presents a unique opportunity for achieving poverty reduction goals through improved market access for small-scale producers. Developing countries have played an important role in the production and trade of this high-value agricultural subsector and, in some cases, have captured a large portion of the horticultural market. For example, Mexico ranks as the world's leading exporter of fresh tomatoes, while Kenya and Guatemala are the major players in the world market for green peas. In addition to global trade opportunities, the growth of supermarkets and the expansion of the middle class have opened up new opportunities for the organization of national- and regional-level horticultural value chains (Reardon and Berdegué, 2002; Evers et al., 2014). Cultivation of fruit and vegetables is substantially more labor-intensive than growing traditional cereal crops and it offers more post-harvest opportunities to add value (von Braun et al., 1989; Weinberger and Lumpkin, 2007; Hamilton and Fischer, 2005). Evidence tends to show that the scale of the farming operations does not pose a barrier to entering the chain, although investments in human capital formation may still be needed for smallholders. Today, value addition through packing and processing services (e.g. washing, chopping, and mixing, bagging, and branding), many of which were previously based in the developed world, are often carried out at source rather than at the end-market destination (Humphrey, 2004).

Generally, VCD in fresh horticulture implies higher levels of risk as compared to other exportoriented sectors with widespread smallholder participation, such as coffee and cocoa. This reflects the perishable nature of horticultural products, strong seasonal price fluctuations, and onerous traceability and food quality and safety regulations (Unnevehr, 2000; García Martínez and Poole, 2004), coupled with poor regulation of agricultural chemicals and hazards related to polluted soil and water in producing countries. Smallholder horticultural farmers confront relatively high costs to obtain reliable access to quality inputs (e.g. germplasm) and services (e.g. credit and technical support), efficient transportation, storage and processing infrastructure, and trained labor for production and processing. And in the absence of cooperative or other type of collective enterprise, certification costs are prohibitive. Previous studies have highlighted the strong role played by larger-scale buyers in determining the conditions under which smallholders engage in the chain, and the potential for buyers to squeeze smallholders out of the chain in the interest of reduced risk and higher efficiency (e.g. Dolan and Humphrey, 2000; Shankar et al., 2011). Nonetheless, efforts to strengthen smallholder participation in horticultural value chains continue to form part of the rural development and food security agenda (World Bank, 2011; SNV, 2012; Gonzalez et al, 2013; IFAD, 2014; Poole, 2017).

Experiences in Nicaragua with the export of fresh taro (Colocasia esculenta) to the USA illustrates the potential and the pitfalls of horticultural VCD. NGOs and private exporters in Nicaragua played a major role in identifying the market opportunity, building the links with local taro buyers, and building smallholder capacity (e.g. through technical assistance to cooperatives). Early analysis indicated that the chain offered a unique opportunity for smallholders to generate income. However, the risks and uncertainties associated with bringing a new product to international buyers were underestimated, and the Nicaragua-based taro value chain functioned for only a few years (2006-2014). Beginning in 2005 and reaching a peak 
of 13,796 MT in 2009, taro exports to the USA tumbled to 1,800 MT by 2016 . Within roughly a decade, the taro boom in Nicaragua had "bust."

This paper examines the rise and fall of the taro value chain from the perspective of complex adaptive systems (Orr et al., this edition). It aims to contribute to deeper discussions on options for more effective VCD with smallholders by focusing on the dynamics of the value chain and the capacities of chain actors and their supporters to anticipate and respond to opportunities and shocks. In particular, we focus on three aspects, namely internal and external shocks at the national and international levels faced by chain actors during the boom, interactions of smallholders, businesses, and service and input providers to organize the production and marketing of taro for distant buyers; and adaptation by individual actors and the system as a whole when confronted by the changes in the external environment. These include the effects of biological and ecosystems, the local or micro socio-economic environment, including human and cultural systems, and the political and legal environment as it relates to business organization and performance. In this work, we do not attempt to address the natural environment directly, but the effects of biological and ecosystem factors are evident in this fresh produce chain.

We focus specifically on three components of the conceptual framework, namely the endogenous shock that triggered the collapse, the interactions between agents that led to this shock, and the attempted response by smallholder producers. In doing so, we reflect on: the interactions of buyers and support organizations in building the chain and fostering its growth and consolidation, the capacity of smallholders and local businesses to engage in the taro value chain over time, and the reasons why the system was ultimately unable to adapt to changes in the internal and external environment. We argue that the collapse of the chain was due primarily to the uncertainty faced in taro production and marketing, and the inability of local stakeholders to anticipate and respond to the shocks that surfaced during the boom. Uncertainty stemmed from various factors, including limited experience in international fresh produce trade, lack of specialized skills in taro production and post-harvest management, and weak linkages between key actors in the chain. These failings reflect pressures on development agencies, and to some extent on private exporters, to identify "quick wins" for investors and to overlook or minimize the time and resources required to build technical capacity and social capital along the value chain. The value chain for taro in Nicaragua was a victim of the "bandwagon effect" in VCD, whereby enthusiasm for simplistic initiatives turns out to be more naïve than realistic.

The paper is organized into six sections. Section 2 describes horticulture value chains as complex systems, and the implications for stakeholders in VCD. Section 3 describes the data used in this study. This is followed by an analysis of the rise and fall of the value chain between 2004 and 2016. After that, we discuss adaptation and why value chain actors were not able to successfully adapt to changing market conditions. The conclusion identifies some key lessons for the design of relatively high-risk value chain interventions with smallholders.

\section{Horticulture value chains as a complex system}

Overall, the value chain literature has paid limited attention to the factors that shape the development trajectory of smallholder value chains and the related implications for VCD stakeholders. "Upgrading" and "governance" - the core tenets of the value chain framework (e.g. Kaplinsky and Morris, 2001) - remain relevant for understanding how chain actors relate to each other. They help to explain the rationale underlying such relations, and the implications for development interventions. However, the value chain framework on its own misses critical elements for the design of effective market-oriented interventions with smallholders, including the capacities of local actors to respond to the demands of downstream buyers and the overall capacity of the system to respond to internal and external shocks. Various guides and tools have been published to help practitioners identify the opportunities for new forms of market 
JADEE 8,1 engagement by smallholders and small-scale enterprises (Donovan et al., 2015). However, these guides typically ignore the various and complex factors and interactions that ultimately determine the capacity of resource poor actors to effectively engage in value chains over time, such as asset endowments and livelihood strategies, the nature of relationships among value chain actors, and access to the right services at the right time. In addition, specific issues inherent in the production and marketing of a given crop, as well as issues related to logistics, infrastructure investments, and production risks, for example, are left for the users to identify. As Poole (2017) notes in other smallholder projects, a lack of consideration of value chain risk management hinders participation, particularly by the poorest and most risk-averse farmers. Systemic value chain risks can be addressed through public investments, improving governance of markets as well as natural resources management, and such planning must be explicit in planning interventions.

The challenge lies in better understanding the multiple and diverse constituents of actors and the overall systems in which they interact. Value chains for manufactured products and services are characterized by strict quality controls and often stable regulatory and political environments, but are still regarded as complex systems (see Brosch et al., 2011; Xiao et al., 2017; Poole, 2017). In contrast, for agricultural commodities, there are extra risk factors. Value chains for food products are subsumed within biological and ecological systems that are unstable, often unpredictable, uncontrollable, and highly interactive. These elements include the effects of climate and weather, perishability and disease, with significant feedback loops that are only partially understood. The human system comprises multiple and diverse actors and other stakeholders in respect of individual cognitive behavior, motivation, and perceptions of risk and risk management. Collective enterprise adds further complexity such as formal cooperative organizations, new patterns of vertical organization, and often multi-level conflict. The diversity of actors includes not only the buyers and sellers within a particular chain, but players who provide services such as finance, technology, information and education. The cultural system within which a chain function has national and business elements as individual and firm-level characteristics, well as norms of business conduct, standards and political and regulatory systems. Frequently these are not harmonized across the boundaries of export and import markets. While coordination is often extolled, the reality of business interaction is often more conflictual, especially when individuals and organizations differ markedly in their capacities and expectations for commercial engagement.

Recently, discussions have shown a growing interest in better understanding the opportunities, motivations, and capacities of smallholders engaged in agricultural marketing systems. Researchers have combined the value chain framework with concepts and frameworks related to innovation systems (e.g. Thiele et al., 2011; Devaux et al., 2016), rural livelihoods (e.g. Bolwig et al., 2010; Jacobsen, 2011; Stoian et al., 2012), and gender equity (Vargas Hill and Vigneri, 2011; Mnimbo et al., 2017). This has provided a more nuanced perspective on the potential and limitations of smallholder engagement. Case studies have highlighted how poorer households tend to be excluded from participation in high-value agricultural markets, mainly due to their limited capacity to assume greater risk and their pursuit of diversified livelihoods strategies (Donovan and Poole, 2014; Tobin et al., 2016). Researchers also have shown how access to value chains and the benefits derived from participation in value chains, such as improved production and greater access to food, can differ within a household based on gender and age (Loconto, 2015; Rutherford et al., 2016). Others have highlighted the potential to deepen VCD impacts by addressing the needs of cooperatives (Donovan et al., 2017) and engaging multiple stakeholders and organizations in the development process, although these benefits may be limited by the institutional constraints and other bottlenecks in the system (Kilelu et al., 2017). Revived discussions around "marketing systems" have placed a strong emphasis on the overall context in which interventions are designed and carried out and on the dynamic nature of systems (Campbell, 2014). 
Our analysis of the rural household draws heavily on the sustainable livelihood framework (SLF), which aims to understand how people adapt their livelihoods to a range of risks, including those linked to markets (Scoones, 1998). We place special attention on the capacity of smallholder households to engage in the value chain and adjust to change over time. Livelihood activities are influenced by multiple factors, including the goals of a particular individual. Although these goals are determined at a household level, they are informed by socio-cultural and socio-economic factors situated in the wider economic, political, and institutional context. The SLF acknowledges the importance of access to assets in shaping livelihood activities (Scoones, 1998). Assets include different types of capital: natural, social, human, physical, and financial. Households pursue chosen outcomes by employing various asset mixes in diverse activities. Activities and asset deployment are driven by people's own capabilities and their vulnerability context, including shocks (e.g. drought), trends (e.g. resource stocks), and seasonal variations (Bebbington, 1999). How resources are accumulated, used, or substituted all contribute to the ways in which households manage risk and opportunities. An early application of an asset framework by Moser (1998) highlighted the relation between asset endowments and vulnerability, where the more assets households possessed in the right combination, the more able they were to respond to the external shocks. More recently, an asset framework has been applied to assess the impacts of agricultural research on rural poverty (Meinzen-Dick and Adato, 2008). Assets have also been analyzed at the household and collective level (Donovan and Poole, 2014; Poole et al., 2007).

Collective enterprises, in this case formal cooperatives, share a central place in our analysis, given their role in encouraging smallholder taro production and engaging with international taro buyers. Without them, there would not have been a taro boom in Nicaragua. In particular, cooperatives negotiated sales with buyers, engaged with NGOs, provided extension services, facilitated access to credit, and offered input subsidies. While the vast literature of rural cooperatives contains many examples of successful experiences, there has been insufficient analysis of the often long and turbulent process by which cooperatives develop over time and the viable options for shortcuts. Too often cooperatives and producer associations are supported by external actors with limited options to continue support once project funds terminate, leading to disrupted service offerings for members, and fragmented learning processes for cooperatives and their partners (Donovan et al., 2017; Donovan et al., 2008; Poole and de Frece, 2010). The development process may be marked by the periods of rapid growth followed by periods of crisis due to incompetence, corruption, or bad luck, leading to prolonged periods of inactivity or dissolution. Building decentralized capacity to engage with key business partners has shown to be a challenge for even well-established cooperatives (Poole and Donovan, 2014). Nonetheless, there is evidence that mature farmer-run cooperatives can assume important roles in agricultural development based around technology generation and product transformation (Bebbington et al., 1996; Molnar et al., 2008). Success is often attributed to external support over prolonged periods (often critical for the formation of physical capital and building links with smallholders), having a strong market orientation, and the consolidation of democratic and professional governance structures.

Our assessment of the external environment in which smallholders and collective enterprises operated covers four elements:

(1) First, the political-legal environment, from investments in infrastructure to market institutions such as the setting of standards for food safety, is a major determinant of the capacity of chain stakeholders to engage in demanding agricultural markets over time (World Bank Group, 2016). The literature highlights various instances where exporters from Latin America gained a foothold in a lucrative horticultural 


\section{JADEE 8,1}

\section{2}

export market, only to lose their footing due to lack of enforcement of standards, changes in the global marketing context, and unanticipated changes in regulations in importing countries (Murray and Hoppin, 1992; Calvin et al., 2003).

(2) Second, reliable access over time to comprehensive and affordable services (e.g. technical assistance, transport, and credit) becomes a critical element for the intensification of smallholder production and growth of collective enterprises. This recognizes the limitations of development agencies, typically operating under tight budgets and timelines, to supply all the services needed by poor farmers and collective enterprises.

(3) Third, the macro market context, including global supply and demand conditions, influences the incentives, as well as the risks, for investment by chain actors. Failure to anticipate and respond to swings in the macro market context can lead to chain collapse. In the late 1990s, for example, the smallholder-dominated fresh pineapple sector of Ghana and Cote d'Ivoire suffered major losses as consumer preferences switched to a new variety that was being exported from plantations in Costa Rica and heavily promoted by EU-based supermarkets (Fold and Gough, 2008).

(4) Finally, the relationships between businesses form a critical element to understanding the opportunities and risks associated with VCD. Chain partnerships can be fragile, resting on the human relationships between key individuals in the businesses, whereby the departure of one of these individuals may result in a decision to terminate the relationship (Gedeon et al., 2009).

\section{Methodology}

Our analysis is based on primary data from household surveys and key informant interviews, supplemented by secondary information. Primary data were collected in two rounds: the first in 2010 and the second in 2016. The 2010 round corresponded to a period of strong taro exports from Nicaragua, while the 2016 round corresponded to a period of markedly lower export sales, where relatively few smallholders participated.

Data collection in 2010 focused on one collective enterprise (a cooperative referred to here as $\mathrm{CE} 1$, for reasons of confidentiality), its members and suppliers, and the international NGO and downstream buyers that engaged with the collective enterprise. Among the 427 households that produced and delivered taro to CE1 at least once between 2006 and 2009, 127 were included in the sample. Since neither CE1 nor its NGO supporter or business partners maintained a roster of taro producers, we selected three areas where households were concentrated, and within each area we attempted to interview all households that delivered some or all of their own taro production to CE1. The first area was located near CE1's processing plant $(<10 \mathrm{~km})$ and included 58 households. The second was located $25-35 \mathrm{~km}$ from the plant, and included 51 households. The third area at $55-75 \mathrm{~km}$ from the plant, included 18 households. The relative modest sample sizes in each stratum are acceptable given that the data are used to understand the range of responses to the changing situation in the taro value chain, rather than extrapolate the findings for the population of producers. Data were collected at roughly the midpoint of the taro boom, and illuminated the growers' ability to participate in the boom and the consequences of their participation, covering landholdings, access to inputs and services, physical capital, and income flows. Data collection covered investments in taro production, taro production systems, household endowments, and livelihood strategies, as well as implications of taro production incomes, assets, and overall resilience.

During the second round in 2016, primary data were collected from all three of the collective enterprises that were engaged in taro export: the cooperative CE1, and CE2 and CE3, both of which were semi-autonomous producer associations attached to local NGOs. 
In addition, data were collected from roughly 57 percent of the households that were interviewed in $2010(n=72)$. Those households not included had either changed residence or were otherwise unavailable after at least two attempts to reach them. Data collected in 2016, after the collapse of the taro export market, provided information about the reasons for dropping out of taro production; strategies employed to reduce risk during the boom; and capacities to engage in new income-earning activities following the collapse of the taro market. The aim was to identify the overall context in which the smallholders operated and their options for future engagement in market-oriented food production. Since the three enterprises began their taro exports around the same time, operated in the close proximity of each other and provided similar services to their members, the data from households from $\mathrm{CE} 1$ are likely to be representative of the households affiliated with the other taro-exporting enterprises.

\section{Shocks: boom and bust}

Complex adaptive systems are characterized by endogenous shocks that originate from within the value chain, often because of conflicts between value chain actors. In the case of taro in Nicaragua, the collapse was triggered by the failure of producers to satisfy the quality requirements of US buyers (an internal shock) as well as an external shock caused by the growing comparative advantage of Mexico in a highly competitive market.

Smallholder horticultural production in Nicaragua received extensive support from bilateral donors and in some cases, from large-scale exporters in Nicaragua, sparked by various factors that converged in the early-mid-2000s. Following the signing of the Central America Free Trade Agreement (CAFTA-DR) in 2005, the US Government pledged financial support to promoting the trade capacity of smallholders and agribusiness in Central America (Office of the US Trade Representative, 2007). Between 1999 and 2004, interest grew in the diversification out of coffee among governments, NGOs, and the private sector in response to the sustained record-low coffee prices (Varangis et al., 2003). Finally, there was a strong demand for traceable sources of horticulture from the growing supermarket sector in Nicaragua, where store numbers increased from roughly 20 in 2004 to 60 in 2009. Supermarkets and their intermediaries turned to smallholders for the supply of fresh products (Hope et al., 2012). During the mid-2000s, taro - a bulky, yet highly perishable tuber, native to South East Asia - seemed like a perfect fit for diversification by smallholders in Northern Nicaragua: they were familiar with the product, it had suddenly become highly valued in export markets, and it could be grown with relative ease in small swampy patches on coffee farms.

Around 2005, Miami-based importers of fresh taro began seeking a new source of product after the sudden collapse of production in the Dominican Republic and Puerto Rico due to the taro leaf blight disease (Singh et al., 2012). Nicaragua-based NGOs were quick to identify a market opportunity for smallholders to supply the US market with smallholder-grown taro from Nicaragua. Flush with bilateral project funds, NGOs sought partnerships with cooperatives, hired consultants to identify bottlenecks for taro production (e.g. lack of processing facilitates, limited production) and marketing, and designed interventions to support new growers, processors, and exporters. NGO-led interventions aimed to facilitate market contacts with potential exporters of taro, build the capacity of local businesses to bulk and process taro, and expand the area under taro production by smallholders. Three major interventions were carried out, one led by an international NGO and the other two led by local NGOs. In one case, smallholder production was channeled through a small cooperative that had been revitalized with NGO support to bulk, clean, and package taro for export. In the other two cases, local NGOs organized their networks of smallholder suppliers to directly export taro to the USA. In some cases, government-financed extension agents were assigned to the collective enterprises to provide technical assistance to smallholders in taro production. 


\section{JADEE 8,1}

Fresh taro exports from Nicaragua to the USA grew rapidly from 2004 and peaked in 2009, reaching about 13,000 MT (Figure 1). During these boom years, producers received high prices as competition to meet export commitments enticed local buyers to pay top dollar. In 2006, for example, prices for taro were roughly US\$20 per $60 \mathrm{~kg}$ sack, compared to US\$5-7 per sack during the period prior to the opening of the export market (Moncada, 2006). Local newspapers heralded the rapid growth of fresh tubers for export, recognizing the benefits that exports had delivered for growers, rural communities (in terms of job creation) and cooperatives, and the contributions of bilateral donors and NGOs to the process. Total taro exports from Nicaragua to the USA averaged US\$9.4 million per year between 2006 and 2011. Processing plants sprang up along roads in rural areas to prepare taro for shipment to the USA.

Some smallholders were able to take advantage of the taro boom to invest in building their stock of productive assets. During the first found of data collection, 23 households were identified has having sold taro to CE1 and purchased land between 2006 and 2009, totaling roughly 73.5 ha. The mean expansion per household across the sample was 3.2 ha, with significant differences found based on pre-existing land holdings (Table I). Six households made relatively large purchases (between 5.6 and 21 ha), while the majority of households purchased between 0.2 and 1.4 ha. In the majority of cases, factors other than taro production made possible the land purchases. For those households, whose primary income source was coffee $(n=6)$, the rapid and sustained increase in coffee prices during the assessment period was a major factor in facilitating land purchases. Income from off-farm sources was a factor in four cases. In four other cases, attribution of the land purchase was made to taro production. Perhaps equally important is that 20 households, or roughly 15 percent of the sample, did not own land at the beginning of the assessment period nor at the end of the period. These households produced taro and other crops, mainly basic grains, on land that was under short term, informal rental or on land loaned by coffee plantation owners.

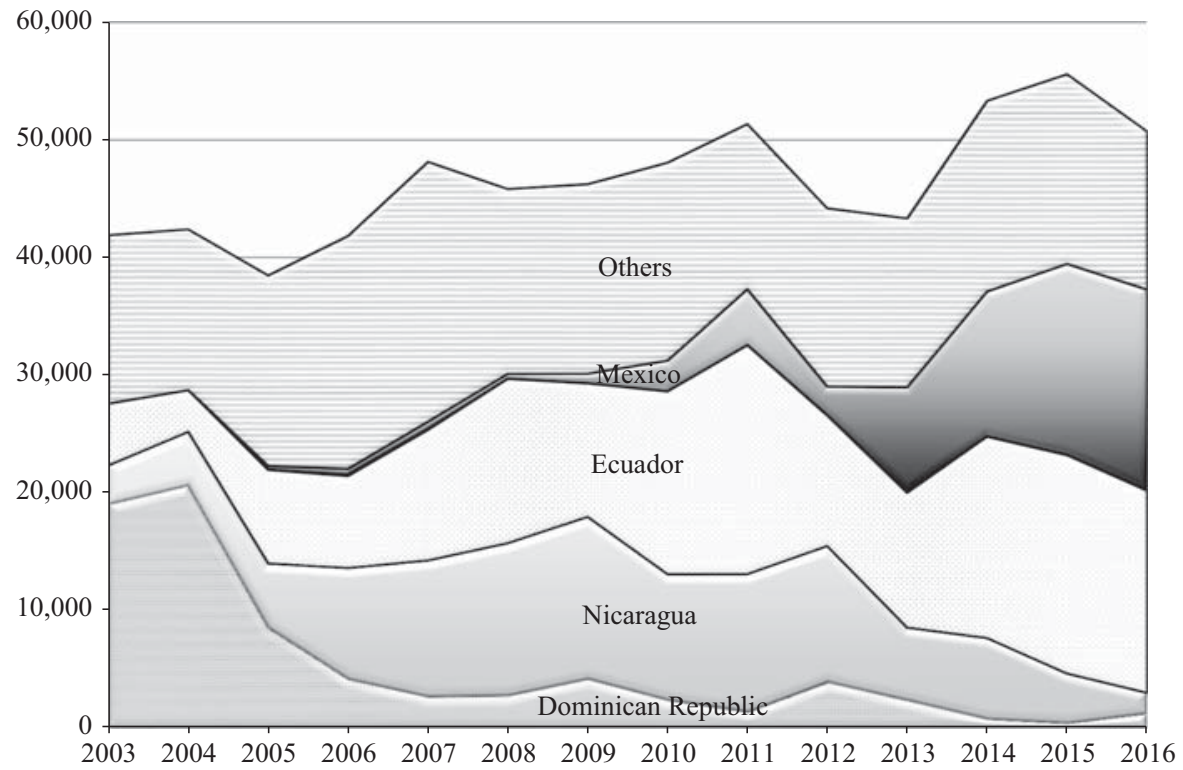

Source: FAS $(2016,2017)$
Figure 1.

Stacked time series of US taro imports (MT), 2003-2016 


\begin{tabular}{|c|c|c|c|c|}
\hline Landholdings 2007 & Number of households & Mean & SD & $\begin{array}{l}\text { Ambition } \\
\text { meets reality }\end{array}$ \\
\hline \multicolumn{4}{|c|}{$\begin{array}{l}\text { Mean land purchase (ha) between } 2006 \text { and } 2009 \\
F=3.98, p<0.05\end{array}$} & \\
\hline Small (0-1.3 ha) & 8 & 0.69 & 0.73 & \\
\hline Medium (1.4-4.1 ha) & 6 & 1.28 & 1.37 & \\
\hline Large $(4.2 \mathrm{ha}+)$ & 9 & 6.74 & 10.81 & \\
\hline Total & 23 & 3.21 & 7.76 & 85 \\
\hline \multicolumn{5}{|c|}{$\begin{array}{l}\text { Mean area (ha) of wetland brought into agricultural production between } 2006 \text { and } 2009 \\
F=8.72, p<0.05\end{array}$} \\
\hline Small & 21 & 0.13 & 0.24 & \\
\hline Medium & 9 & 0.20 & 0.31 & \\
\hline Large & 10 & 0.48 & 0.43 & \\
\hline Total & 40 & 0.23 & 0.37 & \\
\hline \multicolumn{5}{|c|}{$\begin{array}{l}\text { Mean fertilizer application per ha in } 2009 \text { (lbs) } \\
F=1.31, p>0.05\end{array}$} \\
\hline Small & 18 & 1171.00 & 106.09 & \\
\hline Medium & 10 & 548.57 & 259.70 & \\
\hline Large & 15 & 732.20 & 407.77 & \\
\hline Total & 43 & 872.86 & 748.30 & \\
\hline \multicolumn{5}{|c|}{$\begin{array}{l}\text { Mean fertilizer application per ha in } 2008 \text { (lbs) } \\
F=0.77, p>0.05\end{array}$} \\
\hline Small & 20 & 965.86 & 470.25 & Table I. \\
\hline Medium & 13 & 533.84 & 672.00 & ANOVA of selected \\
\hline Large & 15 & 656.71 & 447.14 & indicators of natural \\
\hline Total & 48 & 814.26 & 522.75 & capital \\
\hline
\end{tabular}

Roughly two-thirds of households reported expenditures for farming tools, machinery, and infrastructure between 2006 and 2009. Investments included tools for taro production, as well as for basic grains and coffee production. The average expenditure during this period was US $\$ 461$ per household (Table II). Mean total expenditures varied significantly according to farm size, with small farmers averaging US\$162, compared to US\$394 and US $\$ 1,006$ for medium and large farmers, respectively. Critical for achieving high productivity of taro in dry land is the ability of farmers to irrigate. Only seven households reported access to irrigation equipment during the assessment period. Among the 80 households

\begin{tabular}{|c|c|c|c|c|}
\hline Landholdings 2007 & Number of households & Mean & SD & \\
\hline \multicolumn{5}{|c|}{ Household expenditures for tools, machinery and infrastructure for farm production between 2006-2009 } \\
\hline Small $(0-1.3 \mathrm{ha})$ & 25 & 162.31 & 209.47 & \\
\hline Medium (1.4-4.1 ha) & 25 & 394.56 & 176.47 & \\
\hline Large $(4.2 \mathrm{ha}+)$ & 34 & $1,006.89$ & 449.12 & \\
\hline Total & 84 & 573.29 & 241.18 & \\
\hline \multicolumn{5}{|c|}{$\begin{array}{l}\text { Household expenditures for improvements to, and extension of, home between 2006-2009 } \\
F=5.79, p<0.05\end{array}$} \\
\hline Small & 34 & $1,008.20$ & $1,569.80$ & Table II. \\
\hline Medium & 19 & 636.28 & 934.39 & ANOVA of selected \\
\hline Large & 26 & $3,062.33$ & $4,297.13$ & indicators of physical \\
\hline Total & 79 & $1,594.80$ & $2,873.00$ & capital \\
\hline
\end{tabular}


JADEE 8,1

Table III.

ANOVA of selected indicators of financial capital that produced taro on dry land without irrigation, 45 reported that lack of water was the primary reason for crop failure or for significantly lower than expected yields of first-quality taro. Besides productive capital, secure shelter is a physical asset enabling households to meet their subsistence needs and well-being. The average expenditure per household during the period was US $\$ 1,594$. Mean investments by small farmers exceeded those of medium farmers by nearly 40 percent. Five small farmer households made significant investments in the construction of a new home, with investments ranging from US $\$ 1,205$ to US $\$ 5,882$. In all of these cases, income for the sale of taro was identified as the main contributing factor.

Evidence from 2009 suggested that, in general, the contribution of taro to household income was significant, and averaged US $\$ 1,714$ (Table III). Interestingly, average incomes for small farms were roughly 35 percent larger than the incomes from households with medium holdings. This reflected that some small farmers depended more heavily on taro production for their total income than households with larger holdings and more diversified livelihood strategies. In some cases, the good performance of small farmers was due to access to relatively high-yielding wetlands (also allowing for sales during peak demand). Other households had one-off favorable results from own or rented dry land. For example, one household member began producing taro in her father's wetland patch in 2007, and with the income derived from early taro sales was able to dedicate labor exclusively to on-farm production and then purchase more land for coffee production. In another case, a household member produced taro in 2009 only on rented land with no use of fertilizer. Despite a serious fungus infestation, sales of taro were seven times his income received from agricultural labor, the other income source.

Households that had relatively large endowments of capital prior to the assessment period were the most likely to have benefited from the interventions. Expansion in land under cultivation was mainly financed by non-taro resources, particularly coffee sales, meaning that the asset-poor growers - in respect of landholdings - were disadvantaged. Moreover, large farmers were those principally responsible for the increases in land area devoted to taro. Capacity to invest in physical capital was proportional to the size of the farming enterprise and also other livelihood activities. For some small farmers, taro sales did finance land purchases, and in a few other cases farmers were able to improve domestic infrastructure.

\begin{tabular}{|c|c|c|c|}
\hline Landholdings 2007 & Number of households & Mean & $\mathrm{SD}$ \\
\hline \multicolumn{4}{|c|}{$\begin{array}{l}\text { Total gross income (US\$) derived from taro sales in } 2009 \\
F=7.78, p<0.05\end{array}$} \\
\hline Small (0-1.3 ha) & 32 & $1,204.86$ & $1,446.3$ \\
\hline Medium (1.4-4.1 ha) & 20 & 780.12 & 775.5 \\
\hline Large $(4.2 \mathrm{ha}+)$ & 27 & $3,009.39$ & $3,1182.7$ \\
\hline Total & 79 & $1,714.07$ & $2,295.6$ \\
\hline \multicolumn{4}{|c|}{$\begin{array}{l}\text { Mean percentage of total gross income derived from taro sales } \\
F=1.04, p>0.05\end{array}$} \\
\hline Small & 32 & 40.5 & 30.2 \\
\hline Medium & 20 & 30.2 & 14.5 \\
\hline Large & 27 & 38.0 & 25.9 \\
\hline Total & 79 & 37.1 & 25.5 \\
\hline \multicolumn{4}{|c|}{$\begin{array}{l}\text { Total credit received (2006-2009) for taro production } \\
F=1.35, p>0.05)\end{array}$} \\
\hline Small & 21 & $1,001.12$ & $1,429.5$ \\
\hline Medium & 18 & $1,288.53$ & $1,965.2$ \\
\hline Large & 18 & $1,875.49$ & $1,627.3$ \\
\hline Total & 57 & $1,369.98$ & $1,685.7$ \\
\hline
\end{tabular}


Access to wetlands, hitherto unproductive for other crops, was a major advantage for some households, as wetland production was associated with more intensive input usage, and for that reason was potentially more sustainable, but also potentially over-intensive. While most farmers invested in basic production tools, some small farmers experienced no asset building. Others were forced to sell assets when their taro project failed. In recent years, many of the poorest farmers, confronted with external shocks and limited capacity to invest on farm, have depended more on off-farm income-generating activities. Overall, the evidence for minimum asset thresholds to engage in new initiatives is consistent with the literature (e.g. World Bank, 2007; Winters and Chiodi, 2011, Donovan and Poole, 2014).

However, the taro boom in Nicaragua was short-lived. Beginning in 2012, sales volumes trended sharply downward, while at the same time higher quality, lower cost exports of taro from Mexico (mainly Veracruz, Oaxaca, Tequila, and Sinaloa) to the USA increased markedly (Figure 1). By 2016, Nicaraguan taro sales to the USA had fallen below 2,000 MT per year. As one cooperative member noted in the local press, "Farmers like me are uneasy; we are not planting taro because we are unsure if we can sell it afterwards" (Ewest, 2010). With no local market to divert taro, cooperatives stopped the purchase of taro from smallholders and their processing plants were left idle or refitted for other activities.

By 2016, roughly 83 percent $(n=60)$ of the households sampled in the second period of data collection had stopped producing taro for the market. Household respondents identified the lack of attractive marketing options (low prices, price uncertainty, high costs) as a major reason for their exiting the taro value chain $(n=30)$, as well as high risk in production $(n=16)$, depleted soils, and otherwise lack of suitable land for production $(n=10)$, and other reasons $(n=4)$. Among the 12 households that continued to produce taro in 2016, the majority $(n=10)$ counted modest contributions from taro to annual income, where the average contribution to annual income was roughly US $\$ 163$ in 2016, or roughly 2 percent of their estimated annual income for 2016. For two households, taro sales made a major contribution to annual income in 2016, where in one case taro comprised 50 percent of an estimated household income (US $\$ 2,000$ ), while in the other case it comprised 20 percent of an estimated income (US\$5,827). In both cases, taro was sold to local buyers who bulked taro for exporters with trade links to the Caribbean market, mainly Puerto Rico.

Information is scarce on the exact reasons for the decline of taro exports from Nicaragua. Mexico had produced taro for the export market since the late 1990s, and their taro exporters are likely to have enjoyed lower transportation and production costs, resulting from larger-scale irrigated taro plots, as compared to the Nicaraguan exporters. Around 2010, one Nicaraguan taro producer association and its partner NGO hired specialized consultants to identify options to reduce the taro damage in production, transportation, and processing; however, by then export volumes were already on the decline and local prices for taro were falling. In the next two sections, we use two components of the conceptual framework - interacting agents and adaptation - to analyze the reasons for the collapse of the taro value chain.

\section{Interacting agents}

Smallholder value chains, like complex adaptive systems, are characterized by interacting agents, where the behavior of individual agents is strongly influenced by the behavior of other agents in the chain. In the case of taro in Nicaragua, the failure to build strong relationships between importers, cooperatives, and producers, and the resulting conflicts, are fundamental in explaining in the collapse of the value chain.

\section{Importers and cooperatives}

Importers in Miami grew weary of taro from Nicaragua due to the conditions under which taro was processed and transported, leading to noncompliance with the US quality regulations. Interviews with cooperative leaders highlighted the rejection of several 
JADEE 8,1 containers by importers due to containers with insufficient volume, late shipments (e.g. due to bottlenecks at port in Nicaragua), damaged products discovered at port (mold, decay), and the use of unauthorized chemicals (carbendazim), which ultimately lead to an automatic inspection of Nicaraguan taro shipments when they reached US ports. Both enterprises lost several containers worth of taro due to rejection by buyers for low quality, and with no representation at the port, the enterprises had little recourse but to accept the terms as dictated by the importers. During the middle of the taro boom, one container would have been valued at around US $\$ 35,000$, the loss of which would have likely absorbed a large share of annual profit achieved by a collective enterprise.

Rejections reflected the cooperatives' failure to build strong relationships with US taro buyers characterized by the sharing of information or long-term contracts; rather, prices for taro were determined at port based on market prices, and buyers were able to switch suppliers even while the product was in port. The initial strategy for linking CE1 to the taro value chain rested on its forging a long-term partnership with a large-scale Nicaragua-based coffee exporter. With mediation by its international NGO partner, in 2006, CE1 entered into a buy-sell arrangement with the exporter that called for the cooperative's costs to be shared equally between CE1 and the exporter, as well as all benefits from the export of taro. Between 2006 and 2007 over 75 percent of the total value of CE1 taro went to wholesalers in Miami through the partnership with the exporter, with total taro exports valued at roughly US\$880,000 (Centro Internacinla de Agri- cultura Tropical, 2010). Ultimately, however, the partnership was short lived. By 2008, both partners agreed to terminate collaboration due to suspicions by the exporter that the cooperative's costs were too high; frustration at the cooperative's perceived unwillingness to share information and adjust its practices; and suspicions by the cooperative that the exporter was not forthright in revealing the benefits derived from taro sales. In 2009, the cooperative rejected the arrangement and only sold to the coffee exporter on a cash basis. In the same year, the exporter announced plans to reduce its purchases of taro and establish its own packing shed, thus bypassing the cooperative for the sourcing of taro. However, no investments were actually made and the exporter abandoned the taro business shortly thereafter. Between 2009 and 2013, $\mathrm{CE} 1$ exported directly fresh taro to various wholesale buyers in Miami.

\section{Cooperatives and growers}

Three collective enterprises took part in taro export from Nicaragua. Prior to their engagement in the taro chain, two of the enterprises had exported coffee and cocoa (CE2 and $\mathrm{CE} 3$ ), while the other (CE1) had facilitated the sale of beans for its members in local markets none of the enterprises had participated in the production, processing, or export of taro or any other fresh horticultural product for national or international markets. International NGOs financed the construction of processing plants for all the enterprises, each costing roughly US $\$ 200,000$. In some cases, additional NGO support was provided for working capital, and supplying clear water to the plants. Technical assistance by the NGOs consisted mainly of periodic visits by NGO staff with collective enterprise leaders, and in the case of CE1, providing support to the cooperative to build a business partnership with a Nicaraguan-based coffee exporter who was interested in the export of taro. Overall, international NGO support focused on providing the basic infrastructure for taro export and left the organizational and capacity building to the collective enterprises.

During the peak years of exports, the enterprises purchased taro from between 300 and 600 farmers and employed from 50 to 70 persons in the processing plants. Earnings from taro were reinvested in the provision of on-site technical assistance to a limited number of suppliers, facilitating access to planting materials, and training on production techniques. Impressive volumes of taro exports were achieved, reaching an average of two containers a week during the height of the boom. In 2006, for example, CE1, which had been on the verge of collapse just a few years before, exported 33 containers of fresh taro worth roughly 
1.2 million (Moncada, 2007). However, building social capital with taro growers and with downstream chain actors proved to be a challenge. In the case of CE2 and CE3, strong governance structures for business management and among networks of growers, established through the buying of cocoa and coffee, were in place before the taro boom. However, during periods of high taro demand the networks were frequently insufficient to meet taro volume requirements, thus forcing the enterprises to purchase from farmers outside their network. Sourcing from outside the supplier network implied considerable risk, as farmers had not been trained in proper handling, the consequences of which would not be evident till the shipment arrived at the importing destination.

In the case of CE1, institutional structures were weak prior to the boom and remained so during the boom. No rules existed for decisions on when to export and under what conditions. In some cases, cooperative members used their contacts with buyers and growers to arrange for the export of taro outside the cooperative structure. Cooperative membership, at 42 members during the course of the taro boom, had not changed since its original formation in the 1990s. Thus, the vast majority of CE1's taro suppliers were mere suppliers of raw material and had limited stake in the cooperative's long-term development. The failure to expand membership limited the pressure for institutional development, as well as the credibility of the organization as a promoter of rural development. Finally, the lines between personal and business were ill-defined. One cooperative leader received a personal loan for covering emergency expenses incurred when an order for two container-loads was canceled by the US importer just prior to the close of the fiscal year, resulting in the loss of the entire contents.

By 2013, the collective enterprises had stopped purchasing taro from local smallholders for export to the USA. Interviews with enterprise leaders reflected on the challenges they perceived in the taro value chain. $\mathrm{CE} 1$ drew attention to the challenges it faced in organizing smallholder supply for a new market:

The cooperative was very weak, but we learned how to organize ourselves to respond to the taro market opportunity. It took a while to learn, since everything about the crop was new, and we committed a lot of mistakes in planting and harvesting. We faced a steep learning curve: to ensure high prices, we needed to provide high quality, but we lost sales since we did not understand quality issues at the beginning. There were a lot of buyers looking for taro, and a lot of competition for buying the crop. There was no manual or guide to follow.

CE2 also focused on the struggle to meet quality expectations:

The whole process from harvest to delivery in Miami had be handled cautiously. Sloppy and negligent packing and handling led to low quality at the end. Other NGOs entered the market, who would buy through intermediaries, who, in turn, would buy containers worth of taro and sell at whatever price. Our producers would sell to them as well. [...] The fresh fruit and vegetable market was so new and we knew nothing about it; we had no idea what type of systems and structures were needed for this to be a success.

CE3 drew attention to the challenges based in the larger business environment:

We lacked information on trends, production and markets. We were unable to foresee the growth of taro exports from Mexico and how this would eventually cut everyone here out of the market. [...] To export, we needed a permanent presence with the importer in Miami, a broker. This did not happen in our case [...] We overstretched ourselves: we knew we were good at coffee and cocoa, but had no idea of the complexities of taro.

\section{Taro growers}

Smallholders reacted swiftly and positively to the taro boom. In the absence of irrigation, small patches of swampy land unsuitable for the production of coffee or basic grains were pressed into the production of taro. Growing taro in these wetlands had several advantages over dry land taro production, including higher yields (about double), less weed infestation, 
JADEE 8,1

and the possibility of out-of-season production, resulting in more attractive prices. The organization of the taro value chain allowed 40 households to bring these previously unused areas into economic production (Table I). The number of these wetlands was limited and mean size was small, roughly 0.2 ha. In more than one case, however, wetland production of taro emerged as the most significant source of household income allowing for the purchase of additional land for coffee production and for other forms of asset building.

Taro production demands considerable quantities of fertilizer, with a recommended 430 pounds/ha, applied in three applications during the growing season (first with 15-15-15 at planting, second with 18-46-0 when foliage expands, and finally urea near harvest). Between 2006 and 2009, roughly 28 percent of the households $(n=35)$ reported that they did not apply any fertilizer. In 2009, 43 households applied complete fertilizer to their taro plot. In several cases, the quantity applied was higher than the recommended quantity (Table I). A similar pattern was present in 2008. Where fertilizer was used most intensively, these cases were often characterized by households with small plots of taro production in wetlands, where production costs and risks were relatively low and where the potential benefits from fertilizer use were most easily realized. The relatively high prices paid for taro during the taro boom provided a strong incentive for producers to invest in fertilizers. In the years following 2009, however, as exports began a sustained decline and the risk of failing to find buyers increased, it is likely that household fertilizer application declined in response.

Access to short-term credit facilitated the purchase of fertilizer and other inputs, as well as hired labor for planting and harvest. Between 2006 and 2009, 57 households (45 percent of the sample) reported access to short-term credit for taro, with the mean total credit at US $\$ 1,369$ (Table III). The difference between means across the three subgroups was not statistically significant. This reflects the ability of households with the smallest land holdings to obtain credit for production of taro in wetlands and on dry land, and the overall limited size of taro plantations by households with larger land holdings. Among the 57 households that received credit, all but six households received credit from micro-finance organizations. The Fondo de Desarrollo Local (FDL) had the broadest coverage across the sample, supplying credit to 17 households. However, in $2009 \mathrm{FDL}$ stopped servicing taro producers due to the high risk of default. A major problem for producers of taro on dryland without irrigation was the marketing risk: $\mathrm{CE} 1$ might be unable to purchase their product at harvest time, thus forcing producers to leave taro in the ground (with risk of infection or infestation) or sell to other buyers at lower prices.

All this was achieved without intensive support from cooperatives. CE1 provided professional technical assistance to only a handful of growers. No other taro buyer, government agency, or NGO was identified as having provided information or technical assistance for taro production. Interventions for building the taro value chain channeled through CE1 neglected growers and were largely focused on developing the taro processing capacity of CE1 and on helping CE1 to develop commercial relations with downstream buyers. CE1 and its NGO supporter assumed that basic skills for taro production already existed among smallholders and that new growers could learn basic production techniques with minimum training. Another intervening factor was the lack of technicians with experience in the tuber production. Interviews with representatives of the Ministry of Agriculture and Livestock confirmed the absence of information on best practices for taro production. In no case had the soils of the sampled households been analyzed prior to taro production for determining levels of nutrients and compaction. Interviews with other CEs that participated in the taro boom reflected a similar situation: limited direct support to their grower network, a learning-by-doing approach to processing and marketing, and external support focused on infrastructure development.

\section{Adapting to boom and bust}

Complex systems are adaptive because they can evolve and learn. Adaptation is an essential survival skill in fast-changing markets, like horticulture, and one that was unfortunately 
found wanting among smallholder organizations in Nicaragua seeking to compete in the international market for taro.

In the early years of the taro boom, there was little reason to question the potential for the production of taro to lift smallholders out of poverty: the Caribbean was no longer able to supply the US market, and Nicaragua could, but it needed to act quickly. Strong private sector interest, backed with NGO support, combined with previous experience in the coffee sector helped chain actors in Nicaragua to respond to the opportunity. In the early years of the boom, few could have anticipated the emergence of Mexico as a major supplier: access to reliable data was limited and there was no Nicaraguan presence in the major US port of entry for taro. Project documents recognized the need for implementers and beneficiaries to engage with other NGOs, financial services providers, and the private sector to build productive capacity and expand exports. In the end, strong and lasting private sector collaboration was not possible, the Nicaragua-based coffee exporter make a valiant effort, but ultimately pulling out after three years and Miami-based horticultural buyers preferred arm's length arrangements over long-term contracts. Basic services for actors in the chain were unavailable or underutilized, at least during the early stages of chain development, including credit and specialized technical support in production and processing of fresh tubers. Engagement by government agencies with chain actors consisted mainly in sparsely staffed technical assistance programs for growers and inspections of processing plants. Critical issues around compliance with SPS regulations, design of production technologies on dry land, and acquisition of market intelligence were left to CEs and their NGO supporters.

Both collective enterprises, their business partners, and NGO supporters vastly overestimated the adaptive capacity of the value chain for export of fresh taro to the USA and the need for investment in building capacity before chain engagement. The collective enterprises were ill-equipped to offer the package of services needed to support smallholders in dry-land production of taro. The success of technical assistance depended, in part, on the availability of tried-and-true methods for smallholder taro production, which were lacking. Toward the end of the taro boom, collective enterprises had developed a sophisticated understanding of quality control and the processes and risks involved in fresh taro export. But early mistakes cost the enterprises and their suppliers dearly, and may have played a role in the cooling of relations with US-based importers. The rapid rise and decline of CE1 during the boom years supports previous research on the long-term and discontinuous nature of the development of cooperatives. Endowments of social and human capital were weak at the start of the boom, and represented major obstacles to future growth. The cooperative retained many of the characteristics from its inception in the early 1990s: volunteer management, informal governance structures, limited service offer, and a small membership base. Above all, the experience of $\mathrm{CE} 1$ highlights the need for development actors to better select local partners for engagement in complex and demanding value chains - based on an understanding of the complexities involved and the partner's pre-existing capacity over time, in addition to the existence of cordial relations and local enthusiasm.

Growers faced significant risks in taro production and marketing relative to other commercially oriented on-farm productive activities. Half the respondents interviewed during the second round of data collection ranked the production and marketing risks associated with taro much higher $(n=28)$ or higher $(n=8)$ than other on farm activities. Responses tended to highlight the risks posed by mold, degraded soils, and marketing: "If we do not harvest the taro at the right time, it rots, and in addition, there is the instability in prices, but at least we managed to recover our investment;" "[...] we have to give the taro crop a lot of care; the prices fluctuate considerably; and it is expensive to get the taro from the farm to market"; and "When we grow taro on dry land there is a high risk of mould infestation and drought, which can force us to harvest at times when nobody is buying." 
JADEE 8,1

While risk is inherent in all agricultural activities, some of the risk factors identified here (e.g. lack of suitable land and equipment for production and incapacity to address infestations) posed serious consequences for the poorest of farming households.

Households adapted to risk in producing taro by cultivating a small area of rented land, often less than 0.5 ha, and entering into a joint farming arrangement (where farmers share the cost of inputs and any profits during harvest). The other half of the sample for the second round of data collection considered taro to be of much lower risk. Most of these households $(n=24)$ produced taro in wetland areas, which dramatically reduced the risks associated with drought and mold infestation. The remaining households $(n=16)$ considered taro to be relatively low risk to produce, but high risk to market due to the strong fluctuations in demand in recent years. Better-off households were more able to control the risks of taro production on dry land through irrigation and application of fertilizers and fungicides (e.g. carbendazim).

The lack of technical assistance and information for taro production implied that most households learned through trial and error over several cropping cycles, and by "word-of-mouth" from neighbors, cooperative extension agents, and agrochemical input providers. While it was not possible to evaluate production practices in the field, it can be assumed that households that produced taro consecutively for three or more years (54 households, or roughly 43 percent) accumulated a basic understanding of production techniques. However, "learning-by-doing" often resulted in lost production and income. During the first found of data collection, households reported significant losses of taro from improper seed selection/treatment and/or soil compaction $(n=33)$, improper planting distance and input application, or soil leveling $(n=3)$, and exposure to vermin and theft $(n=11)$. The effects of improper taro seed selection, with resulting soil contamination, often endured for several planting cycles.

In the wake of the taro boom, between 2012 and 2015, growers adapted by diversifying their income streams and on-farm productive activities. In total, 19 respondents, or 26 percent of the 2016 sample, engaged in at least one new farm activity where all or part of the production was marketed. Many of these households $(n=10)$ experimented in horticultural production, often with mixed or low levels of satisfaction (e.g. due to high input costs, low prices at harvest and pests and diseases). The remainder diversified into cocoa, coffee production, and rice production - more traditional options with generally more favorable perceptions of outcomes. Overall, farming makes a smaller contribution to household income: for the households in the 2009 sample, roughly 30 percent of total gross income was derived from off-farm activities, while in the 2016 sample off-farm activities comprised roughly 60 percent of income. In addition to contraction of the taro market, rising input costs, proliferation of coffee-related diseases (coffee rust), and drought are likely to have negatively impacted farm production.

\section{Conclusion: learning from failure}

Getting it wrong is part of getting it right (Charles Handy).

The taro boom provided a rare opportunity for NGOs looking to help smallholders generate more income and diversify their on-farm production. In the mid-2000s, high demand for taro in the USA and the existence of taro in swamplands in Nicaragua meant that interventions in the taro chain held considerable promise to raise incomes and generate new economic activity in an otherwise economically depressed region. The market data, level of sales, and real-income benefits attested to the potential value of the chain. Production did not require major fixed investments and was familiar to local farmers - both factors being important prerequisites for success according to the existing guides and tools for designing value chain interventions. Organization of the chain turned 
taro production from a subsistence crop to one that was able to generate significant incomes, including for some people who had no prior land endowments. Moreover, there was strong collaboration and buy-in from the private sector in the development of the chain: large-scale exporters in Nicaragua showed interest in taro and collective enterprises were willing to invest in building infrastructure, organizing supply, and exporting significant quantities of taro. The NGO-led interventions to organize the chain played a catalytic role in bringing about these outcomes. The achievements were all the more noteworthy given the risks and uncertainty of exporting fresh horticulture, the overall difficult business environment in Nicaragua, and the dynamic nature of external markets.

The perspective of complex adaptive systems helps unravel the reasons behind the collapse of taro in Nicaragua. Ultimately, the taro chain only lasted a few years, a consequence of both external factors (emergence of Mexico as a major supplier to the USA) and internal factors (insufficient capacity to engage over time in the highly competitive and demanding fresh horticulture trade). From the vantage of hindsight, one could easily spot gaps in intervention design: insufficient technical support to farmers, lack of horticultural specialists to guide in the production and processing of taro, absence of representation in the US port of entry, and lack of contingency plans for dealing with unexpected changes in the single destination market, among others. Moreover, those engaged in designing interventions in the taro chain could have better anticipated the risks and challenges of exporting fresh horticultural products - after all, these have been well documented in the literature (e.g. Gonzalez et al., 2013). These failings left the value chain dangerously exposed and unable to adapt quickly to shocks.

However, it would be a mistake to write-off the taro case as an example of improper design, an example of those in the field not employing "best practices" in VCD. Donor pressure is another factor: NGOs, government agencies, and private consultancy and finance organizations engaged in developing value chains operate under tight budgets and timeframes and face pressure to show quick results in terms of increased income generation by smallholders.

A perspective based on complex adaptive system forces organizations and business engaged in VCD with smallholders to confront dilemmas in designing interventions in value chains that have been ignored in the existing guides and design tools. In the case analyzed here, the option to invest in building a new value chain that linked smallholders with international markets offered an opportunity for those (better-off) producers willing and able to take the risk (e.g. taro and others forms of fresh horticulture). However, donors, NGOs, and other partners needed to be better prepared to facilitate the capacity of local actors to mitigate risks and respond to unexpected events and stimuli generated from within system: biological and ecosystem variations, human systems and idiosyncratic individual and firm behavior, and the prevailing - but variable - and competing business environments. Where development agencies and private sector actors are unable or unwilling to make the long-term investments needed, alternative development options should be pursued.

Moreover, in this paper, having set aside considerations of changes in biological and ecosystems, it is worth noting that the growing awareness of the acute impacts of climate change in Central America signifies increasing risk complexities that were barely recognized a decade ago when this research was envisaged. We now know that sustainability in value chains such as taro will require much investment in climate-smart agricultural and environmental management techniques. This requires more not only from farmers and their organizations, but also support from researchers, policy makers, and technologists, and the finance and insurance sector, among other public and private stakeholders. 
JADEE 8,1
Taro in Nicaragua serves as reminder to practitioners, donors, researchers, and the private sector on how to identify market opportunities and the design of effective strategies to respond to them. Interventions targeting better-off farmers, and encouraging poorer farmers to take risks that they can ill-afford, are the strategies that raise important issues that are both ethical and economic. Consequences of production and marketing risks can be the impoverishment of the intended beneficiaries through lower and fluctuating incomes, the opportunity costs of ignoring more secure enterprises, the sunk costs of investments in short term initiatives, and, not least, the personal and social costs of failure - all of which can be borne least by the least-endowed households (Poole, 2017). The current set of tools and methods says little about how NGOs and their partners should evaluate risk and uncertainty in value chains or engage with partners in the design of value chains when complex production and marketing settings create high levels of risk and uncertainty. Greater attention is needed as regards the willingness of downstream buyers to engage and share risks, and form sustainable business linkages; and to build the capacity of smallholders and collective enterprises to manage risks and adapt to changes in the environment; and provide specialized services to inform the design and implementation process.

Practitioners, as well as researchers, will benefit from a more critical look at the underlying assumptions of their interventions for building sustainable value chains (e.g. market growth, inter-business relations, smallholder capacity), thus opening the door to alternative planning scenarios, better risk mitigation and adaptation strategies, and, ultimately, more viable and impactful interventions. This will require greater patience and openness on the part of donors and public sector agencies to discuss with NGOs and researchers the errors, unknowns, and dilemmas faced in VCD, willingness on the part of researchers to engage with those in the field in trying to identify the "dos and do nots" for designing interventions in VCD under different contexts, and encouragement of donors for deeper dialogue and cooperation among stakeholders.

\section{Acknowledgement}

This paper forms part of a special section "Smallholder value chains as complex adaptive systems." This study was made possible through funding from the CGIAR global research program "Policies, institutions, and markets" (PIM) and a grant from the Ford Foundation. Donovan was employed as a Research Leader for Value Chains and Transformational Change at the World Agroforestry Center (ICRAF), Lima, Peru, when this research was designed and the second phase of data collection was implemented. During the first phase of data collection, Donovan and Herrera were the Researcher and Consultant, respectively, at the Tropical Agricultural Research and Higher Education Center (CATIE), Turrialba, Costa Rica. The paper has benefited from the suggestions and comments by Alastair Orr and two anonymous reviewers of this journal.

\section{References}

Bebbington, A. (1999), "Capitals and capabilities: a framework for analyzing peasant viability, rural livelihoods and poverty", World Development, Vol. 27 No. 12, pp. 2021-2044.

Bebbington, Quisbert, J. and Trujillo, G. (1996), "Technology and rural development strategies in a small farmer organization", Public Administration and Development, Vol. 16 No. 2, pp. 195-213.

Bolwig, S., Ponte, S., Du Toit, A., Riisgaard, L. and Halberg, N. (2010), "Integrating poverty and environmental concerns into value chain analysis: a conceptual framework", Development Policy Review, Vol. 28 No. 2, pp. 173-194. 
Brosch, M., Beckmann, G., Griesbach, M., Dalhöfer, J. and Krause, D. (2011), "Design for value chain", Zeitschrift für wirtschaftlichen Fabrikbetrieb, Vol. 106 No. 11, pp. 855-860, doi: 10.3139/ 104.110650.

Campbell, R. (2014), A Framework for Inclusive Market Systems Development, USAID, Washington, DC, available at: www.enterprise-development.org/wp-content/uploads/Market_Systems_ Framework.pdf (accessed August 8, 2017).

Calvin, L., Flores, L. and Foster, W. (2003), Case Study: Guatemalan Raspberry and Cyclospora. 2020 Focus 10 Brief 7, IFPRI, Washington, DC.

Centro Internacinla de Agri- cultura Tropical (2010), ACORDAR: Relaciones que dan fruto: Sistemaizacion de una experiencia de construcción de cadenas de valor, CIAT, Cali, Colombia, available at: http://dapa.ciat.cgiar.org/wp-content/uploads/2013/12/compendio-sistematizacionacordar-2010.pdf (accessed January 13, 2017).

Coles, J. and Mitchell, C. (Eds) (2011), Markets and Rural Poverty: Upgrading in Value Chains, Earthscan and International Development Research Centre, London and Ottawa.

Devaux, A., Torero, M., Donovan, J. and Horton, D. (2016), Innovation for Inclusive Value Chain Development, IFPRI, Washington, DC.

Department for International Development (2008), Private Sector Development Strategy Prosperity for All: Making Markets Work, London.

Dolan, C and Humphrey, J. (2000), "Trade in fresh vegetables: the impact of UK supermarkets on the African Horticulture Industry”, Journal of Development Studies, Vol. 37 No. 2, pp. 147-176.

Donovan, J. and Poole, N.D. (2014), "Changing asset endowments and smallholder participation in higher value markets: evidence from certified coffee producers in Nicaragua", Food Policy, Vol. 44, February, pp. 1-13.

Donovan, J., Blare, T. and Poole, N.D. (2017), "Stuck in a rut: emerging cocoa cooperatives in Peru and the factors that influence their performance", International Journal of Agricultural Sustainability, Vol. 15 No. 2, pp. 169-184, doi: 10.1080/14735903.2017.1286831.

Donovan, J., Stoian, D. and Poole, N.D. (2008), "Global review of rural community enterprises: the long and winding road to creating viable businesses, and potential shortcuts”, Technical Series 29/ Rural Enterprise Development Collection 2, CATIE, Turrialba.

Donovan, J., Franzel, S., Cunha, M., Gyau, A. and Mithofer, D. (2015), "Guides for value chain development: a comparative review", Journal of Agribusiness in Developing and Emerging Economies, Vol. 5 No. 1, pp. 1-22, doi: 10.1108/JADEE-07-2013-0025.

Evers, B., Opondo, M., Barrientos, S., Krishnan, A., Amoding, F. and Ndlovu, L. (2014), "Global and regional supermarkets: implications for producers and workers in Kenyan and Ugandan horticulture", Capturing the Gains, University of Manchester, Manchester, available at: www. capturingthegains.org/pdf/ctg-wp-2014-39.pdf

Ewest, G.C. (2010), "Exportación de malanga en descenso", La Prensa, Managua, Nicaragua, February 19, available at: www.laprensa.com.ni/2009/02/27/economia/1356300-exportacion-demalanga-en-descenso

FAS (2016), "USDA Foreign Agricultural Service”, available at: https://apps.fas.usda.gov/gats/ default.aspx;www.cggc.duke.edu/pdfs/2011-11-10_CGGC_Fruit-and-Vegetables-GlobalValue- (accessed February 16, 2017)

FAS (2017), "Foreign agricultural service 2017. Global agricultural trade systems (database)", available at: https://apps.fas.usda.gov/Gats/default.aspx

Fold, N. and Gough, K. (2008), "From smallholders to transnationals: the impact of the changing consumer preferences in the EU on Ghana's pineapple sector", Geoforum, Vol. 39 No. 5, pp. 1687-1697.

García Martínez, M. and Poole, N.D. (2004), "The development of private fresh produce safety standards: implications for developing Mediterranean exporting countries", Food Policy, Vol. 29 No. 3, pp. 229-255. 

$\underset{8,1}{\text { JADEE }}$

Gedeon, I.-M., Fearne, A. and Poole, N.D. (2009), "The role of inter-personal relationships in the dissolution of business relationships", Journal of Business and Industrial Marketing, Vol. 24 Nos 3/4, pp. 218-226.

Gonzalez, A., Zuniga, T. and Wilson, G. (2013), Advancing Horticulture: Assessment of Constraints to Horticultural Sector Growth in Central America, Feed the Future Innovation Lab for Collaborative Research on Horticulture, University of California, Davis.

Hamilton, S. and Fischer, F. (2005), "Maya farmers and export agriculture in highland Guatemala: implications for development and labour relations", Latin American Perspectives, Vol. 32 No. 5 , pp. 33-58.

Hope, M., Reardon, T. and Perez, F. (2012), "Small farmers and big retail: trade-offs of supplying supermarkets in Nicaragua", World Development, Vol. 40 No. 2, pp. 342-354.

Humphrey, J. (2004), "Upgrading in global value chains", Working Paper No. 28, International Labour Organization, Geneva.

IFAD (2014), "Smallholder horticulture marketing programme: supervision report", available at: http://operations.ifad.org/documents/654016/f26b9d66-d971-45f9-a615-c07bcf60f1ed

Jacobsen, S.E. (2011), "The situation for quinoa and its production in Southern Bolivia: from economic success to environmental disaster", Journal of Agronomy and Crop Science, Vol. 197 No. 5, pp. 390-399.

Kaplinsky, R. and Morris, M. (2001), "A handbook for value chain research", report prepared for International Development Research Centre, Ottawa, available at: www.ids.ac.uk/ids/global/ pdfs/ValuechainHBRKMMNov2001.pdf

Kilelu, C., Klerkx, L., Omore, A., Baltenweck, I., Leeuwis, C. and Githinji (2017), "Value chain upgrading and the inclusion of smallholders in markets: reflections on contributions of multi-stakeholder processes in dairy development in Tanzania”, The European Journal of Development Research, Vol. 29 No. 5, pp. 1102-1121, doi: 10.1057/s41287-016-0074-z.

Loconto, A. (2015), "Can certified tea value chains deliver gender equality in Tanzania", Feminist Economics, Vol. 21 No. 3, pp. 191-215.

Meinzen-Dick, R. and Adato, M. (2008), Agricultural Research, Livelihoods, and Poverty: Studies of Economic and Social Impacts in Six Countries, Johns Hopkins University Press, Baltimore, MD, pp. 388.

Mnimbo, T.S., Lyimo-Macha, J., Urassa, J.K., Mahoo, H.F., Tumbo, S.D. and Grael, F. (2017), "Influence of gender on roles, choices of crop types and value chain upgrading strategies in semi-arid and sub-humid Tanzania”, Food Security, Vol. 9 No. 6, pp. 1173-1187, doi: 10.1007/s12571-017-0682-2.

Molnar, A., Gomes, D., Sousa, R., Vidal, N., Rorster-Hojer, R., Arguelles, L.A., Kaatz, S., Martin, A., Donini, G., Sherr, S., White, A. and Kaimowitz, D. (2008), "Community forest enterprise markets in Mexico and Brazil: new opportunities and challenges for legal access to the forest", Journal of Sustainable Forestry, Vol. 27 Nos 1/2, pp. 87-121.

Moncada, M.A. (2006), "Tubérculos con Dinamismo Exportador", La Prensa, Managua, Nicaragua, May 3, available at: www.laprensa.com.ni/2006/05/03/economia/1464864-tuberculoscon-dinamismo-exportador

Moncada, M.A. (2007), "Instalan planta para procesar tubérculos", La Prensa, Managua, Nicaragua, May 19, available at: www.laprensa.com.ni/2007/05/19/economia/1300816-instalan-planta-paraprocesar-tuberculos

Moser, C. (1998), “The asset vulnerability framework: reassessing urban poverty reduction strategies", World Development, Vol. 26 No. 1, pp. 1-19.

Murray, D. and Hoppin, P. (1992), "Recurring contradictions in agrarian development: pesticide problems in Caribbean basin non-traditional agriculture”, World Development, Vol. 20 No. 4, pp. 597-608.

Office of the US Trade Representative (2007), "Building trade capacity under the CAFTA-DR", CAFTA-DR facts, CAFTA policy brief, July, available at: https://ustr.gov/archive/assets/Trade_ Agreements/Regional/CAFTA/Briefing_Book/asset_upload_file891_7353.pdf 
Poole, N. (2017), Smallholder Agriculture and Market Participation, Practical Action and United Nations Food and Agriculture Organization, Rugby and Rome.

Poole, N. and Donovan, J. (2014), "Building cooperative capacity: the specialty coffee sector in Nicaragua", Journal of Agribusiness in Developing and Emerging Economies, Vol. 4 No. 2, pp. 133-156.

Poole, N.D. and de Frece, A. (2010), A review of Existing Organizational Forms of Smallholder Farmers' Associations and their Contractual Relationships with Other Market Participants in the East and Southern African ACP Region, FAO, Rome.

Poole, N.D., Gauthier, R. and Mizrahi, A. (2007), "Rural poverty in Mexico: assets and livelihood strategies among the Mayas of Yucatán”, International Journal of Agricultural Sustainability, Vol. 5 No. 4, pp. 315-330.

Reardon, T. and Berdegué, J. (2002), "The rapid rise of supermarkets in Latin America: challenges and opportunities for development", Development Policy Review, Vol. 20 No. 4, pp. 371-388.

Rutherford, D.D., Burke, H., Cheung, K. and Field, S. (2016), "Impact of an agricultural value chain project on smallholder farmers, households and children in Liberia", World Development, Vol. 83, July, pp. 70-83.

Scoones, I. (1998), "Sustainable rural livelihoods: a framework for analysis", IDS Working Paper No. 72, Institute of Development Studies, Brighton.

Shankar, B., Posri, W. and Srivong, T., "A case study of a contract farming chain involving supermarkets and smallholders in Thailand", Canadian Journal of Development Studies, Vol. 31 Nos 1-2, pp. 137-153.

Singh, D., Jackson, G., Hunter, D., Fullerton, R., Lebot, V., Taylor, M., Iosefa, T., Okpul, T. and Tyson, J. (2012), "Taro leaf blight: a threat to food security", Agriculture, Vol. 2 No. 3, pp. 182-203.

SNV (2012), "Supporting the vegetable value chains: approaches, lessons and innovations in Svay Rieng", available at: www.snv.org/public/cms/sites/default/files/explore/download/supporting the_vegetable_value_chain_in_svay_rieng_final.pdf

SNV (Netherlands Development Organization) (2005), Private Sector Development: Finding Quality Advisory Approaches, SNV East and Southern Africa, Nairobi.

Stoian, D., Donovan, J., Fisk, J. and Muldoon, M. (2012), "Value chain development for rural poverty reduction: a reality check and a warning”, Enterprise Development and Microfinance, Vol. 23 No. 1, pp. 54-69.

Thiele, G., Devaux, A., Reinoso, I., Pico, H., Montesdeoca, F., Pumischo, M., Andrade-Piedra, J., Velasco, C., Flores, P., Esprella, R., Thomann, A., Manrique, K. and Horton, D. (2011), "Multi-stakeholder platforms for linking small farmers to value chains: evidence from the Andes", International Journal of Agricultural Sustainability, Vol. 9 No. 3, pp. 423-433.

Tobin, D., Glenna, L. and Devaux, A. (2016), "Pro-poor? Inclusion and exclusion in native potato value chains in the central highlands of Peru", Journal of Rural Studies, Vol. 46, August, pp. 71-80.

Unnevehr, L. (2000), "Food safety issues and fresh food product exports from LDCs", Agricultural Economics, Vol. 23 No. 3, pp. 231-240.

USAID (2008), "Key elements of the value chain approach", briefing paper, USAID, Washington, DC.

Vargas Hill, R. and Vigneri, M. (2011), "Mainstreaming gender sensitivity in cash crop market supply chains", ESA Working Paper No. 11-08, FAO, Rome.

Varangis, P., Siegel, P., Giovannucci, D. and Lewin, B. (2003), "Dealing with the coffee crisis in Central America: impacts and strategies", World Bank Policy Research Working Paper No. 2993, World Bank, Washington, DC.

Von Braun, J., Hotchkiss, D. and Immink, M. (1989), "Nontraditional export crops in Guatemala: effects on production, consumption and nutrition", research report, IFPRI, Washington, DC.

Weinberger, K. and Lumpkin, T.A. (2007), "Diversification into horticulture and poverty reduction: A research agenda”, World Development, Vol. 35 No. 8, pp. 1464-1480. 
JADEE 8,1

98

Winters, P.C. and Chiodi, V. (2011), "Human capital investment and long-term poverty reduction in rural Mexico", Journal of International Development, Vol. 23 No. 4, pp. 515-538.

World Bank (2007), World Development Report 2008: Agriculture for Development, World Bank, Washington, DC.

World Bank (2011), "Understanding gender in agricultural value chains: the cases of grapes/raisins, almonds and saffron in Afghanistan", Report No. 62323-AF, available at: http://siteresources.worldbank.org/ AFGHANISTANEXTN/Resources/305984-1326909014678/AFGenderValueChain.pdf

World Bank Group (2016), Enabling the Business of Agriculture 2016: Comparing Regulatory Good Practices, World Bank, Washington, DC, available at: http://eba.worldbank. org/ /media/WBG/AgriBusiness/Documents/Reports/2016/EBA16-Full-Report.pdf (accessed January 24, 2014).

Xiao, H., Sun, T., Meng, B. and Cheng, L. (2017), "Complex network analysis for characterizing global value chains in equipment manufacturing", PLoS One, Vol. 12 No. 1, p. e0169549, available at: https://doi.org/10.1371/journal.pone.0169549

\section{About the authors}

Jason Donovan is a Senior Economist, Markets and Value Chains at the International Maize and Wheat Improvement Center (CIMMYT) in Mexico. His main research interests are rural livelihoods, agricultural markets, business development, and seed systems. Prior to joining CIMMYT, he worked at ICRAF in Peru and CATIE in Costa Rica. Jason Donovan is the corresponding author and can be contacted at: j.donovan@cgiar.org

Nigel Poole works in the Centre for Development, Environment and Policy at SOAS University of London, where he is a Professor of International Development. He is currently researching agrifood and nutrition policy processes and value chain development in South Asia, and leads a working group on Afghanistan.

Keith Poe is a Market and Business Consultant, based in Managua, Nicaragua. He has worked extensively with the Mennonite Economic Development Associates (MEDA), OXFAM and CRS in projects related to cacao, coffee, sisal, cassava and sesame.

Ingrid Herrera-Arauz is an Agronomist and Consultant based in Matagalpa, Nicaragua. Between 2010 and 2015, she led field work for CATIE and ICRAF aimed at shedding light on the implications of export-oriented development interventions for smallholders and cooperatives engaged in coffee and taro.

For instructions on how to order reprints of this article, please visit our website:

www.emeraldgrouppublishing.com/licensing/reprints.htm

Or contact us for further details: permissions@emeraldinsight.com 